\title{
Recurrence based entropies for sustainability indices
}

\author{
Vasily Derbentsev ${ }^{1}$, Serhiy Semerikov ${ }^{2}$, Olexander Serdyuk ${ }^{3}$, Victoria Solovieva $^{4,},{ }^{*}$, and Vladimir Soloviev ${ }^{2}$ \\ ${ }^{1}$ Kyiv National Economic University named after Vadym Hetman, 54/1 Peremogy Ave., Kyiv, 03057, Ukraine \\ ${ }^{2}$ Kryvyi Rih State Pedagogical University, 54 Gagarina Ave., Kryvyi Rih, 50086, Ukraine \\ ${ }^{3}$ Bohdan Khmelnitsky National University of Cherkasy, 81 Shevchenko Blvd., Cherkasy, 18031, Ukraine \\ ${ }^{4}$ Kryvyi Rih Economic Institute of Kyiv National Economic University named after Vadym Hetman, 16, Medychna Str., Kryvyi Rih, \\ 50000, Ukraine
}

\begin{abstract}
The work is devoted to a comparative analysis complexity of traditional stock market indices and social responsible indices in the example Dow Jones Sustainability Indices and Dow Jones Industrial Average. As measures of complexity, the entropies of various recurrence indicators are chosen - the entropy of the diagonal lines of the recurrence diagram, recurrence probability density entropy and recurrence entropy. It is shown that these measures make it possible to establish that the socially responsive Dow Jones index is more complex. A comprehensive assessment of complexity reveals the nature of the effectiveness of social responsible indices and opens up new opportunities for investor risk management.
\end{abstract}

\section{Introduction}

Current economic trends have convincingly demonstrated that green development is a necessary condition for sustainable development, which is essential for a better life in the future [1]. Economists have described climate change as a global market failure estimating that without action, the rising overall costs of climate could result to losing at least $5 \%$ of global GDP each year. A growing number of financial institutions is joining in a constructive dialogue on the relation between economic development, environmental protection and sustainable development. Financial institutions, including banks, insurers, and investors, work with the United Nations Environment Programme - Finance Initiative to better understand environmental, social and governance challenges, why they matter to finance, and how to take steps to address them [2].

The availability of stock indexes based on sustainability screening makes increasingly viable for institutional investors the transition to a portfolio based on a Socially Responsible Investment (SRI) benchmark at relatively low cost.

The 2008 subprime crisis and increased social awareness have led to a growing interest in topics related to socially responsible investment. SRI is a long-term investment that integrates environmental, social and corporate governance criteria (ESG). According to the Global Sustainable Investment Alliance (GSIA), SRI reached 24 trillion euro's in 2016, registering a growth of $25.2 \%$ between 2014 and 2016. So, green and sustainable finance is more important nowadays than ever before [3].

This increased social interest coincides with international initiatives aimed at developing environmental and social policies on sustainable finance issues, such as the Action Plan on sustainable finance adopted by the European Commission in March 2018. This plan has three main objectives:

(i) to redirect capital flows towards sustainable investment to achieve sustainable and inclusive growth, (ii) to manage financial risks stemming from climate change, environmental degradation and social issues, and (iii) to foster transparency and long-termism in financial and economic activity. Therefore, the main purpose is to enhance the role of finance and to build an economy that enables the goals of the Paris Agreement (2015) and the EU for sustainable development to be reached [4].

The Dow Jones Sustainability World Index comprises global sustainability leaders as identified by SAM. It represents the top $10 \%$ of the largest 2,500 companies in the S\&P Global BMI based on long-term economic, environmental and social criteria [5]. Founded in 1995, RobecoSAM is an investment specialist focused exclusively on Sustainability Investing [6].

The S\&P Global Broad Market Index (BMI) is the only global index suite with a transparent, modular structure that has been fully float adjusted since 1989 . This comprehensive, rules-based index series employs a transparent and consistent methodology across all countries and includes more than 11,000 stocks from 25 developed and 25 emerging markets [7]. The SAM Corporate Sustainability Assessment (CSA), established by RobecoSAM, is now issued by S\&P Global. RobecoSAM, an asset manager focused entirely on sustainable investing, established the CSA in 1999. The CSA has become the basis for numerous S\&P ESG Indices over the last two decades attracting billions of USD in assets. In addition, S\&P Global acquired RobecoSAM's ESG Ratings and Benchmarking businesses which operate out of S\&P Global Switzerland.

* Corresponding author: vikasolovieva2027@gmail.com 
SAM is a registered trademark of S\&P Global. ESG (environmental, social and governance) is a generic term used in capital markets and used by investors to evaluate corporate behaviour and to determine the future financial performance of companies. In the conditions of a wide variety of sustainable development indices, it is extremely important for investors to have a comparative characteristic of traditional indices with sustainable development indices obtained by quantitative methods. At the same time, the set of tools of modern financial analysis took shape in a separate rapidly growing applied science - fintech. Financial technology ("fintech") is emerging as a core disruptor of every aspect of today's financial system. Fintech covers everything from mobile payment platforms to high-frequency trading (HFT), and from crowdfunding and virtual currencies to blockchain. In combination, such forceful innovations will threaten the viability of today's financial sector business models, and indeed the effectiveness of current policies, regulations and norms that have shaped modern finance. The use of financial technology innovations is of course not new but a step change is now expected with the novel application of a number of technologies in combination, notably involving blockchain, the Internet of things (IoT) and artificial intelligence (AI) [8]. The widespread introduction of fintech makes it possible to talk about green finance as a strategy for financial sector and broader sustainable development that is relevant around the world [9-12]. Green economy, green finance and green development are the peculiar coordinates of the phase space in which today it is generally accepted to evaluate the sustainable development of world civilization.

Our research structured as follows. Section 2 contains a brief description of socially responsive indexes and an analysis of previous work on a comparative quantitative analysis of this variety of indices. Section 3 describes algorithms for constructing entropy measures of complexity based on the properties of the recurrence of a phase portrait of a time series. Entropy measures introduced are calculated on the basis of the DJIA and DJSI indices. Section 4 summarizes the results obtained and indicates the direction of subsequent studies.

\section{Social responsible indices}

In the last 20-25 years, a huge number of social responsible or sustainability indices have been created and their number continues to grow [13, 14]. Briefly consider the most commonly used.

The Dow Jones Sustainability Indices (DJSI) are a family of best-in-class benchmarks for investors who have recognized that sustainable business practices are critical to generating long-term shareholder value and who wish to reflect their sustainability convictions in their investment portfolios (http://www.sustainabilityindices.com/). The family was launched in 1999 as the first global sustainability benchmark and tracks the stock performance of the world's leading companies in terms of economic, environmental and social criteria. Dow Jones Sustainability World Index, the most important global stock market valuation index of corporate social responsibility.

FTSE4Good was created by the FTSE Group to facilitate investments in companies that meet globally recognised corporate responsibility standards and constitutes an important reference point for the establishment of benchmarks and ethical portfolios. Companies in the FTSE4Good Index have met stringent environmental, social and governance criteria, and are therefore potentially better positioned to capitalise on the benefits of responsible business practice (http://www.ftse.com/).

MSCI is a leading provider of investment decision support tools to investor globally, including asset managers, banks, hedge funds and pension funds. MSCI Global Sustainability Indexes include companies with high ESG ratings relative to their sector peers (http://www.msci.com/).

CDP (formerly the "Carbon Disclosure Project") is one of the world's leading not-for-profit climate change organizations, assessing transparency in the disclosure of information on climate change and greenhouse gas emissions, as well as in the management of water resources (http://www.cdp.net/).

United Nations Global Compact 100 (“GC 100”), a global stock index developed and released by the UN Global Compact in partnership with the research firm Sustainalytics (https://www.unglobalcompact.org/). The index lists the 100 companies which globally outstand for executive leadership commitment and consistent baseline profitability, as well as their adherence to the Global Compact's ten principles, on human rights, labour, environment and anti-corruption issues.

STOXX Global ESG Leaders Indices, a group of indices based on a fully transparent selection process of the performance, in terms of sustainability, of 1,800 companies worldwide (http://www.stoxx.com/). The ratings are calculated for three sub-areas - environmental, social and governance - and are then combined to form the overall index. The indices are managed by STOXX, the owner of some of the most important international stock indices, such as the STOXX50.

In our work, we will carry out a comparative analysis of the index DJSI [15] with its classic and traditional counterpart - the index Dow Jones Industrial Average (DJIA) [16].

\subsection{State of the art}

In a comparative analysis of structural and dynamic properties of traditional stock market indices and social responsible indices, descriptive statistics methods are used in most works [17-20].

Descriptive statistics (mean, maximum, minimum and standard deviation) of the financial information required to apply the Ohlson [17] valuation model reviewed in [18]. They were examining whether sustainability leadership - proxied by membership of the Dow Jones Sustainability Index Europe - is value relevant for investors on the 10 major European stock markets over 
the 2001-2013 period. Our overall results reveal that there exist significant differences across markets.

The article [19] analyzes rate-of-return and risk related to investments in socially responsible and conventional country indices. The socially responsible indices are the DJSI Korea, DJSI US and Respect Index, and the corresponding conventional country indices are the Korea Stock Exchange Composite KOSPI, Dow Jones Industrial Average and WIG20TR. Shown, that conclude that investing in the analyzed SRI indices do not yield systematically better results than investing in the respective conventional indices, both in terms of neoclassical risk and return rate.

The authors [20] examined sustainable investments returns predictability based on the US DJSI and a wide set of uncertainty and financial distress indicators for the period January 2002 to December 2014. They employ a novel nonparametric causality-in-quantile approach that captures non-linearities in returns distribution. Based on our findings we conclude that the aggregate Economic Policy Uncertainty (EPU) indicator and some components have predictive ability for real returns of the US sustainable investments index. Paper [21] explores the relationship between sustainability performance and financial performance by looking at the impact of sustainability index changes on the market value of a company. The author has studied the price effects of changes in the DJSI and FTSE4Good Index. He failed to observe statistically significant positive abnormal returns for companies being added to a sustainability index. On the opposite he finds negative abnormal returns for companies being deleted from the FTSE, however not in the case of the DJSI. This can be explained by studying the volume effects and the behavior of investment managers.

However, the first works appeared using more modern methods of analysis, using the achievements of nonlinear dynamical systems and complexity theory [22-27]. The authors [22] constructed a sustainable regional green economy development index system from five aspects; economic, social, technological, resources, and environmental; using DPSIR (drivers, pressures, state, impact, response model) and entropy-TOPSIS (technique for order preference by similarity to an ideal solution)coupling coordination to horizontally and vertically quantitatively analyze the sustainable green economy development. The model was verified by the actual situation of green economy development in Shandong Province from 2010 to 2016, which confirmed the feasibility of the method.

A sustainable development capacity measure model for Sichuan Province was established by applying the information entropy calculation principle and the Brusselator principle [23]. Each subsystem and entropy change in a calendar year in Sichuan Province was analyzed to evaluate Sichuan Province's sustainable development capacity. It was found that the established model could effectively show actual changes in sustainable development levels through the entropy change reaction system, at the same time this model could clearly demonstrate how those forty-six indicators from the three subsystems impact on the regional sustainable development, which could make up for the lack of sustainable development research.

A similar approach is implemented to measure the tourist attractiveness of the region [24]. And in work [25] information and entropy theory used for the sustainability of coupled human and natural systems.

Authors' [26] used R/S analysis to calculate the Hurst exponent as a measure of persistence (efficiency of traditional stock market indices and social responsible stock market indices). The presence of persistence was evidence in favor of less efficiency. According to empirical results, SRI has lower efficiency, in particular the Dow Jones Sustainability Index. Lower efficiency was also observed in the emerging markets with a responsible investment segment, compared to the traditional stock market indices.

In paper [27] authors suggest three new indicators based on an engineering approach of irreversibility. They allow evaluating both the technological level and the environmental impact of the production processes and the socio-economic conditions of the countries. Indeed, they are based on the energy analysis and on the irreversible thermodynamic approach, in order to evaluate the inefficiency both of the process and of the production systems, and the related consequences. Three applications are summarized in order to highlight the possible interest from different scientists and researchers in engineering, economy, etc., in order to develop sustainable approaches and policies for decision makers.

\section{Comparative analysis complexity of traditional stock market indices and social responsible indices}

As an analysis of previous studies shows, there is no systematic comparative analysis of traditional and persistent indexes, which is primarily due to the use of uninformative methods. In a series of recent works [2831], we have demonstrated the possibility of using the theory of complex systems and a set of developed analysis tools to calculate the corresponding measures of system complexity. These complexity measures make it possible to differentiate systems according to the degree of their functionality, to identify and prevent critical and crisis phenomena.

As an example of such a quantitative measure, we give the well-known entropy measure of complexity approximate entropy [32]. For the daily DJSI and DJIA time series $S(t)$ for the period 03 January $1994-07$ February 2020 (Figure 1), the approximate entropy calculated by the sliding window algorithm is shown in Fig. 2.

The returns over some time scale $\Delta t$ is defined as the forward changes in the logarithm of $S(t)$ $G(t) \equiv \ln S(t+\Delta t) / \ln S(t) \quad$ Since different indices have different levels of variability (standard deviations), we will determine standardized returns $g(t) \equiv[G(t)-\langle G\rangle] / \sigma$, where $\sigma \equiv \sqrt{\left\langle G^{2}\right\rangle-\langle G\rangle^{2}}$ is the standard deviation $G$, and $\langle\ldots\rangle$ denotes the average over the time period under study. 


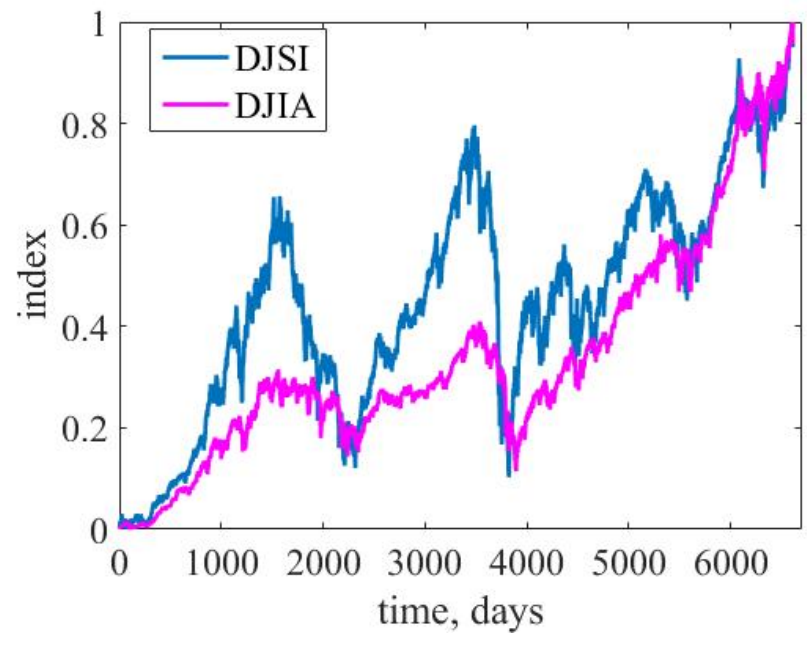

Fig. 1. Comparative dynamics of daily values of stock indices DJSI and DJIA.

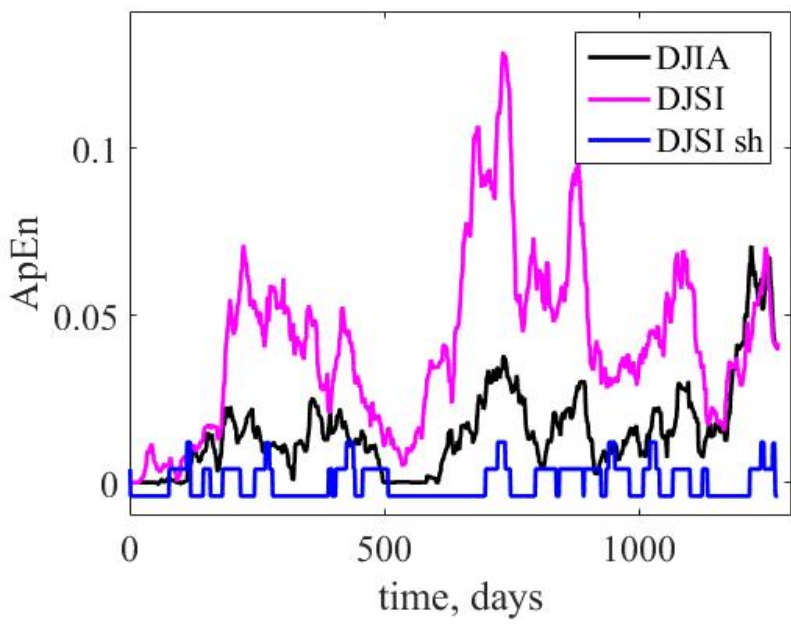

Fig. 2. The approximate entropy (ApEn) indices DJIA and DJSI calculated for a window of 250 days in increments of 5 days. DJSI sh represents the entropy of the shuffled (sh) time series.

The use of such complexity measures has become relevant in view of the fact that time series of similar complexity are statistically almost indistinguishable. For example, the distribution of the normalized returns of the indices presented in Fig. 1 is almost identical (Fig. 3), while the entropy measures solve the problem.

In this paper, recurrence properties, for concreteness, entropy indicators are used as measures of the complexity of stock indices.

\subsection{The family of recurrence entropies}

In recent years, new quantifiers of nonlinear time series analysis have appeared based on properties of phasespace recurrences [33]. According to stochastic extensions to Taken's embedding theorems the embedding of a time series in phase space can be carried out by forming timedelayed vectors

$$
\vec{X}_{n}=\left[x_{n}, x_{n+\tau}, x_{n+2 \tau}, \ldots, x_{n+(M-1) \tau}\right]
$$

for each value $x_{n}$ in the time series, where $M$ is the embedding dimension, and $\tau$ is the embedding delay. These parameters are obtained by systematic search for the optimal set. Figure 4 shows a phase portraits of the DJSI index and its normalized logarithmic returns.

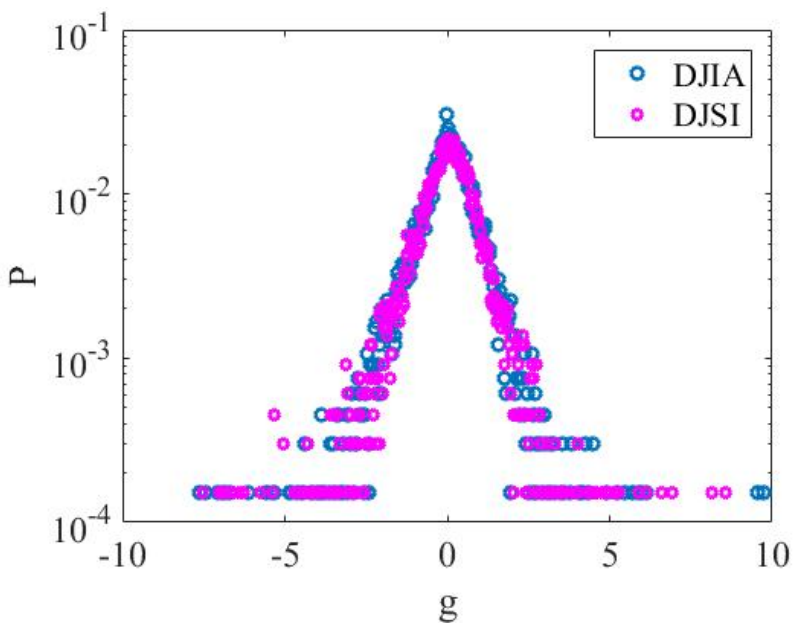

Fig. 3. Distribution functions $P$ of the normalized profitability indices DJIA and DJSI.
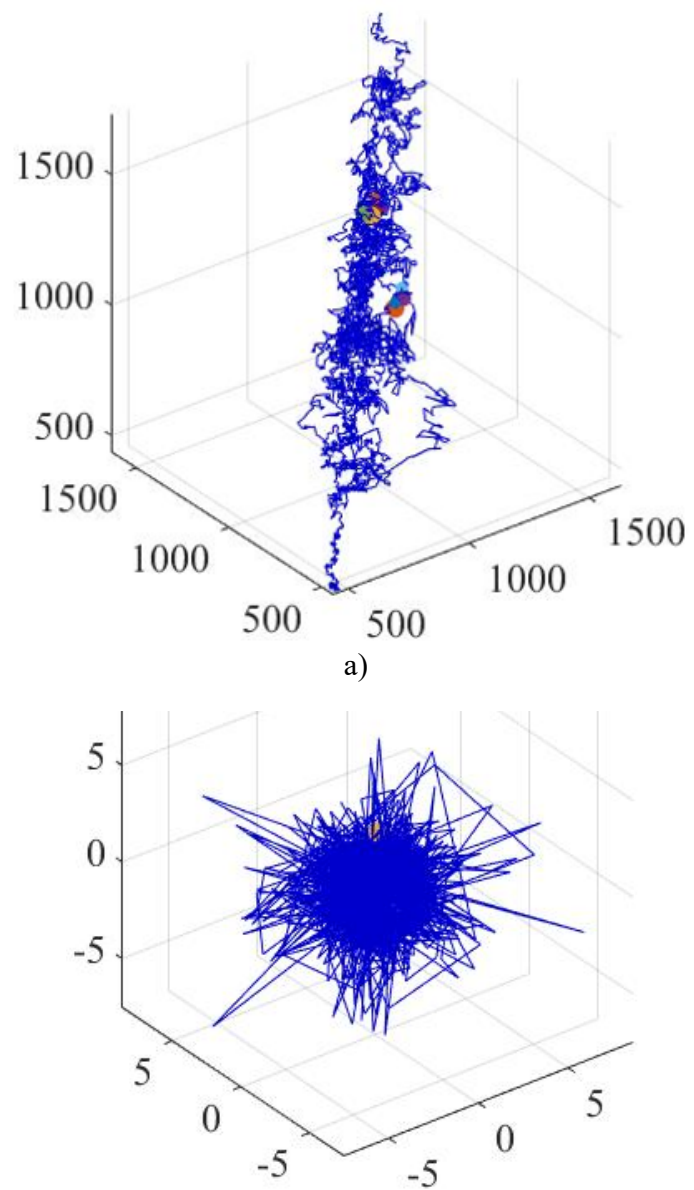

b)

Fig. 4. A phase portraits of the DJSI index (a) and its normalized logarithmic returns (b).

A modern visualization method known as recurrence plots (RP), and is constructed from the recurrence matrix $\vec{R}_{i j}$ defined as 


$$
\vec{R}_{i j}(\varepsilon)=\Theta\left(\varepsilon-\left\|x_{i}-x_{j}\right\|\right), \quad i, j=1,2, \ldots, M,
$$

where $x_{i}$ and $x_{j}$ represent the dynamical state at time $i$ and $j, \Theta$ is the Heaviside function, $M$ is length of the analyzed time series and $\varepsilon$ is the threshold or vicinity parameter, consisting of a maximum distance between two points in a trajectory such that both points can be considered recurrent to each other.

The graphical representation of the RP allows to deriving qualitative characterizations of the dynamical systems. For the quantitative description of the dynamics, the small-scale patterns in the RP can be used, such as diagonal and vertical lines. The histograms of the lengths of these lines are the base of the recurrence quantification analysis [33]. Based on the statistical properties of the recurrence plot, a large number of quantifiers have been developed to analyze details of a RP. Many of them, deal with statistical properties such as mean size, maximum size, frequency of occurrence of diagonal, vertical or horizontal recurrence lines. An important class of recurrence quantifiers is those that try to capture the level of complexity of a signal. As an example, we mention the already known entropy based on diagonal lines statistics. This quantity has been correlated with others dynamical quantifiers as, for example, the largest Lyapunov exponent, since both capture properties of the complexity level of the dynamics. The vertical (horizontal) lines in $R_{i j}$ are associated to laminar states, common in intermittent dynamics [33].

\subsubsection{Entropy of the diagonal lines}

It was reported the use of the distribution of diagonal lines $P(l)$ for a different quantifier of recurrences, based on the Shannon entropy [33]. If we choose a distribution of diagonals

$$
p(l)=P(l) / \sum_{l=1}^{K} P(l)
$$

for $K$ the maximum length of the diagonal lines, then we get one of the known quantitative indicators of recurrence analysis:

$$
E N T R=-\sum_{l=l_{\min }}^{l=l_{\max }} p(l) \ln p(l)
$$

However, as follows from the analysis of entropy indicators, the results are not always possible to coordinate with the proposed models.

To the pleasure of the researchers, it turned out that depending on the technology of using the properties of the recurrence of the phase space, different types of recurrence entropies are distinguished [33].

The following results are obtained for windows of 500 days in increments of 5 days.

The entropy of the diagonal lines for the time series of the DJIA and DJSI is presented in Figure 5.

\subsubsection{Recurrence probability density entropy}

Recurrence probability (or period) density entropy (rpde) is useful for characterising the extent to which a time series repeats the same sequence [34]. Around each point $x_{n}$ in the phase space, an $\varepsilon$-neighbourhood (an $m$ dimensional ball with this radius) is formed, and every time the time series returns to this ball, after having left it, the time difference $T$ between successive returns is recorded in a histogram. This histogram is normalised to sum to unity, to form an estimate of the recurrence period density function $P(T)$. The normalised entropy of this density

$$
H_{\text {norm }}=-\left(\ln T_{\max }\right)^{-1} \sum_{t=1}^{T_{\max }} P(t) \ln P(t)
$$

is the rpde value, where $T_{\max }$ is the largest recurrence value.

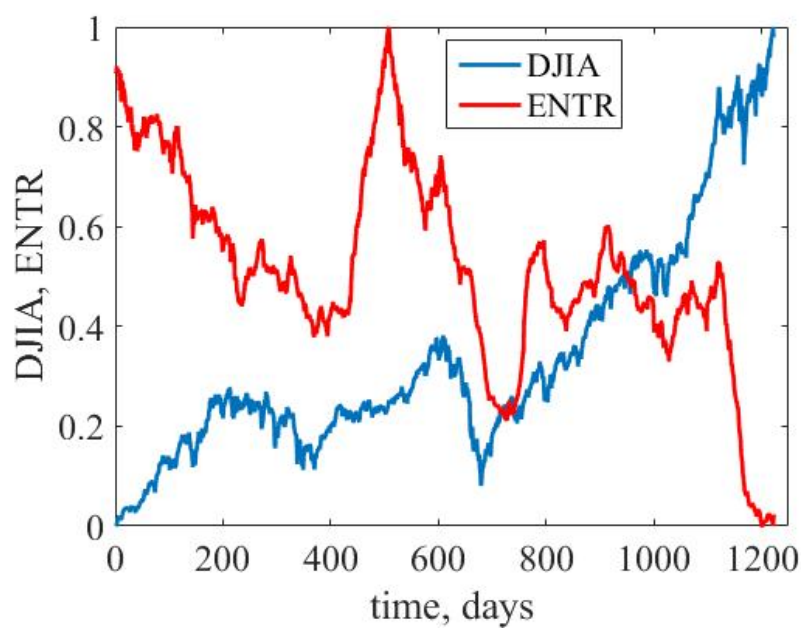

a)

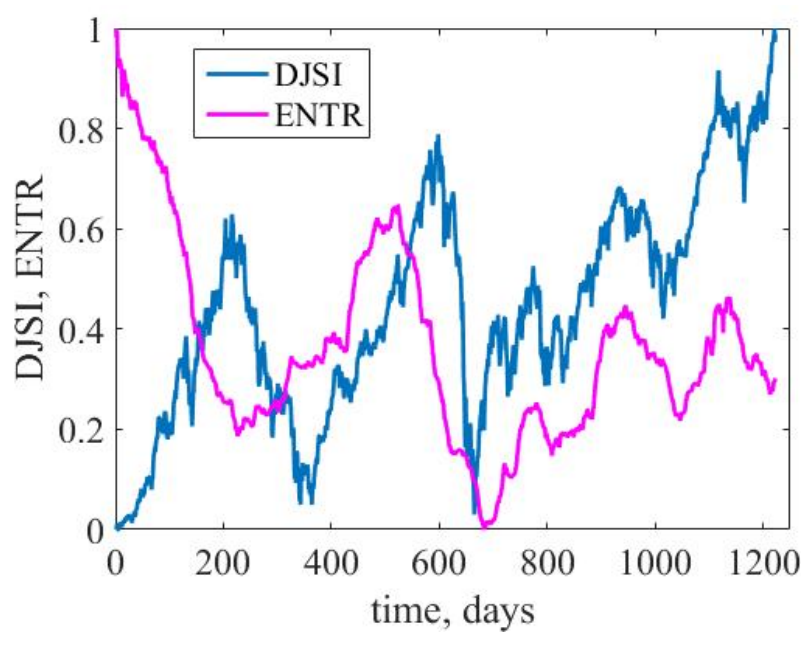

b)

Fig. 5. The entropy of the diagonal lines for the time series of the DJIA (a) and DJSI (b).

The window dynamics of recurrence probability density entropy for the time series of the DJIA and DJSI are given in Figure 6.

\subsubsection{Recurrence entropy}

Recent work [35] presents a slightly different technique 
for calculating recurrent entropy using a novel way to extract information from the recurrence matrix. The authors have generalize these concepts recurrence defining recurrence microstates $F(\varepsilon)$ as all possible crossrecurrence states among two randomly selected short sequences of $N$ consecutive points in a $K$ length time series, namely $F(\varepsilon)$ are $N \times N$ small binary matrices. The total number of microstates for a given $N$ is $N_{m s}=2^{N^{2}}$. The microstates are populated by $\bar{N}$ random samples obtained from the recurrence matrix such that $\bar{N}=\sum_{i=1}^{N_{m s}} n_{i}$, where $n_{i}$ is the number of times that a microstate $i$ is observed. For $P_{i}=n_{i} / \bar{N}$, the probability related to the microstate $i$, we define an entropy of the RP associated with the probabilities of occurrence of a microstate as

$$
S\left(N_{m s}\right)=\sum_{i=1}^{N_{m s}} P_{i} \ln P_{i}
$$

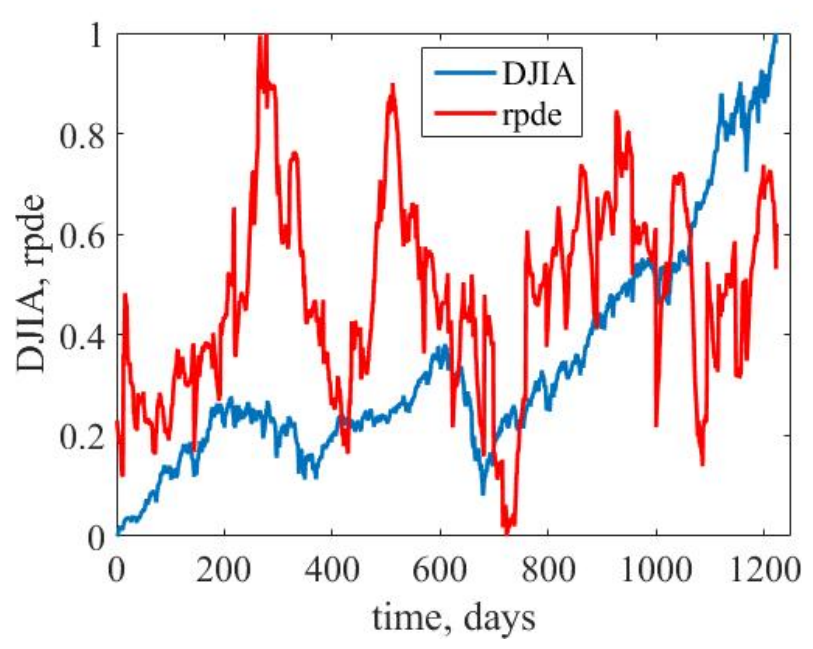

a)

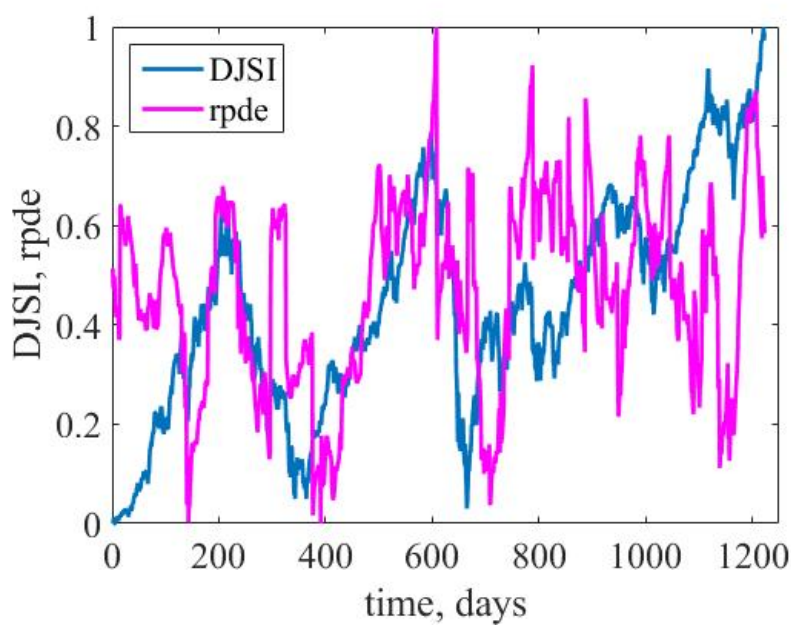

b)

Fig. 6. The recurrence probability density entropy for the time series of the DJIA (a) and DJSI (b).

Entropy recurrence time behavior for the analyzed time series is shown in Figure 7.

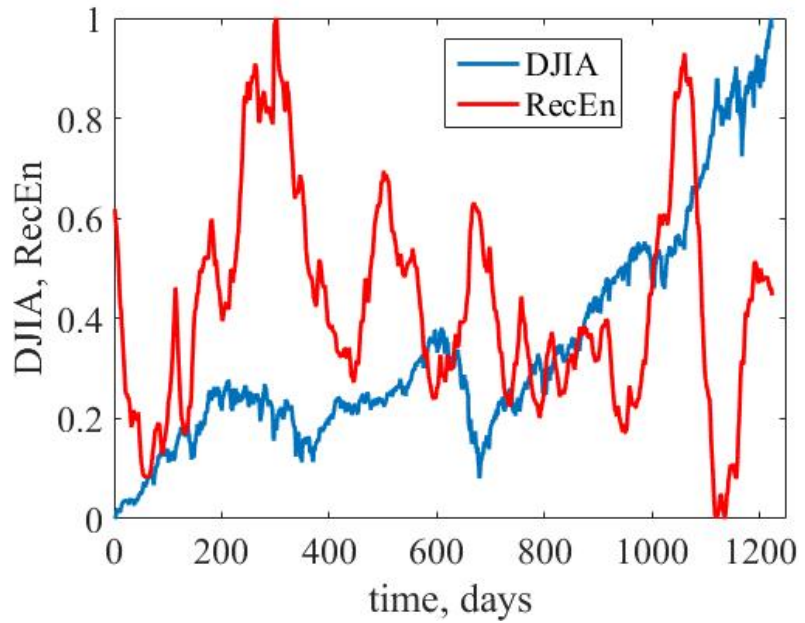

a)

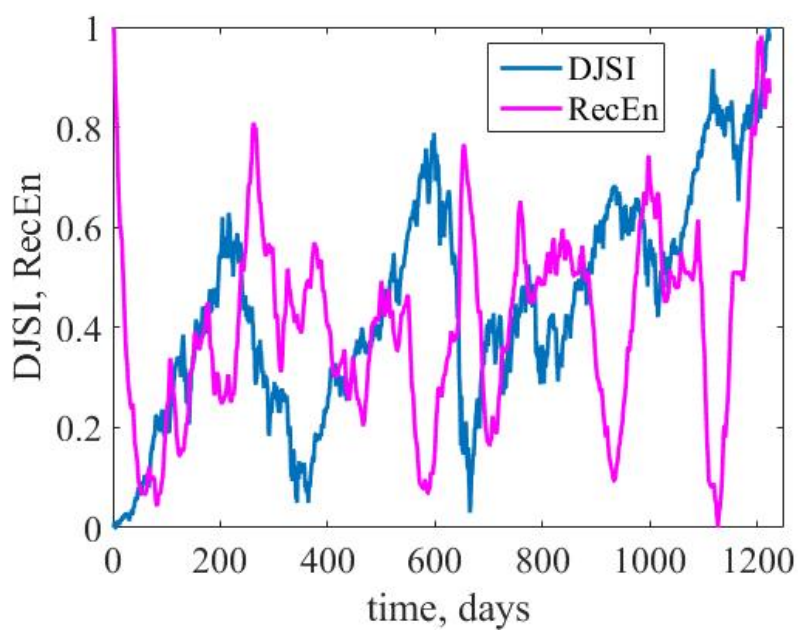

b)

Fig. 7. The recurrence entropy for the time series of the DJIA (a) and DJSI (b).

Similarly, one can obtain the dynamics of recurrent entropies for normalized returns.

An analysis of the results indicates that the time series of the DJSI index is more complex than its classical counterpart DJIA. Moreover, the entropy indicators obtained from the analysis of the recurrence properties of the series themselves are sensitive to changes in its complexity and can serve as measures of entropy complexity.

The pattern of fluctuations of the calculated measures of complexity substantially depends on the size of the movable window. For a more detailed analysis of closein-time noticeable fluctuations in the time series, the window size should be reduced and, on the contrary, a smoothed picture is observed with increasing window size.

These fluctuations are usually associated with critical and crisis phenomena. The fact that entropy measures respond to these phenomena can serve as the basis for constructing an indicator and precursors of crisis phenomena in stock markets [28-31]. 


\section{Conclusions}

In this paper, for the first time, entropy measures of complexity based on the analysis of recurrent properties of time series are used for a comparative analysis of sustainable development indices and their classical analogues. Three varieties of the recurrence base of entropies are considered: the entropies of diagonal lines, the recurrence probability density entropy, and recurrence entropy. Using the DJIA and DJSI indices as an example, it is shown that, firstly, all entropy measures are complexity measures and, secondly, they respond to critical and crisis conditions of the stock market.

In the future, a similar study for a set of other indices would be of interest, as well as a comparison with the results of using other quantitative measures of complexity.

\section{References}

1. RobecoSAM, The Sustainability Yearbook 2019 (2019),

https://yearbook.robecosam.com/fileadmin/Files/Do cuments/2019/The_Sustainability_Yearbook_2019.p df. Accessed 10 Apr 2020

2. The Global Green Finance Index (2020), https://greenfinanceindex.net/survey/. Accessed 10 Apr 2020

3. E. Ercrig-Olmedo, M.A. Fernandez-Izquierdo, I. Ferrero-Ferrero, J.M. Rivera-Lirio, M.J. MunozTerres, Sustainability 11, 915 (2019)

4. L. Fabregat-Aibar, M.G. Barbera-Marine, A. Terceno, L. Pie, Sustainability 11, 2526 (2019)

5. Dow Jones Sustainability Indices (2019), https://en.wikipedia.org/wiki/Dow_Jones_Sustainabi lity_Indices. Accessed 10 Apr 2020

6. RobecoSAM, About us (2020), https://www.robecosam.com/en/about-us/aboutrobecosam.html. Accessed 10 Apr 2020

7. S\&P Global BMI (USD) (2020), https://us.spindices.com/indices/equity/sp-globalbmi-usd. Accessed 10 Apr 2020

8. J.C. Castilla-Rubio, S. Zadek, N. Robins, Fintech and sustainable development - assessing the implications (UNEP Inquiry, Nairobi, 2016)

9. O.Y. Kung, Green finance for a sustainable world (2019), https://www.mas.gov.sg/news/speeches/201 9/green-finance-for-a-sustainable-world. Accessed 10 Apr 2020

10. Green Finance Taskforce, Accelerating Green Finance (2019), https://www.gov.uk/government/pu blications/accelerating-green-finance-green-financetaskforce-report. Accessed 10 Apr 2020

11. D. Nassiry, ADBI Working Paper Series 883 (2018)

12. T. Cen, R. He, Advances in Social Science, Education and Humanities Research 291 (2018)

13. R. Durand, L. Paugan, H. Stolowy, Strategic management J. 40, 1471 (2019)
14. Sustainalytics, Index Research Services (2020), https://www.sustainalytics.com/index-researchservices/. Accessed 10 Apr 2020

15. Dow Jones Sustainability World (^W1SGI) (2020), https://finance.yahoo.com/quote/\%5EW1SGI/. Accessed 10 Apr 2020

16. Dow Jones Industrial Average (^DJI) (2020), https://finance.yahoo.com/quote/\%5EDJI?p=^DJI. Accessed 10 Apr 2020

17. J.A. Ohlson, Contemporary Accounting Research 18(1), 107-120 (2001)

18. M.M. Miralles-Quiros, J.L. Miralles-Quiros, I.G. Arraiano, Business Strategy and the Environment 26(7), 1014-1028 (2017). doi:10.1002/bse.1964

19. P. Sliwinski, M. Lobza, International Journal of Management and Economics 53(1), 25 (2017). doi:10.1515/ijme-2017-0003

20. N. Antonakakis, V. Babalos, C.K. Kyei, Appl. Econ. (2016)

21. J. Tillmann, Master Thesis, University of Tilburg (2012), http://arno.uvt.nl/show.cgi?fid=127657. Accessed 10 Apr 2020

22. M. Wang, X. Zhao, Q. Gong, Z. Ji, Sustainability 11, 280 (2019)

23. X. Liang, D. Si, X. Zhang, Int. J. Environ. Res. Public. Health 14, 1219 (2017)

24. H. Feng, X. Chen, P. Heck, H. Miao, Sustainability 6, 8980 (2014)

25. A.L. Mayer, R.P. Donovan, C.W. Pawlowski, Ecology and Society 19, 11 (2014)

26. H. Mynhardt, I. Makarenko, A. Plastun, Investment Management and Financial Innovations 14, 94 (2017)

27. U. Lucia, G. Grisolia, Energy Reports 5, 62 (2019)

28. V. Soloviev, A. Belinskyi, CEUR-WS, 2014, 116 (2018)

29. A. Belinskyi, V. Soloviev, S. Semerikov, V. Solovieva, CEUR-WS, 2422, 420 (2019)

30. V. Soloviev, A. Belinskij, CCIS, 1007, 276 (2019)

31. V. Soloviev, A. Belinskyi, V. Solovieva, CEUR Workshop Proceedings 2393, 434 (2019)

32. S.M. Pincus, Proc. Acad. Sci. USA 88, 2297 (1991)

33. N. Marwan, M.C. Romano, M. Thiel, J. Kurths, Phys. Rep. 438(5-6), 237 (2007)

34. M.A. Little, P.E. McSharry, S.J. Roberts, D.A.E. Costello, I.M. Moroz, BioMedical Engineering Online 6(23), 1-19 (2007)

35. S.R. Lopes, T.L. Prado, G. Corso, G.Z dos S. Lima, J. Kurths, Chaos, Solitons \& Fractals 133, 109616 (2020). doi:10.1016/j.chaos.2020.109616 